\title{
Evolución Histórica de las Tecnologías Educativas en México
}

\section{Historical Evolution of Educational Technologies in Mexico}

\author{
Juan Fernando Abarca-Reyes ${ }^{1}$
}

\section{อ \\ EDICIÓN: 曲:CIVTAC}

Recibido: 9/agosto/2020

Aceptado: 26/agosto/2020

Publicado: 25/septiembre/2020

${ }^{1}$ México

\section{IIIIInstitución}

${ }^{1}$ Unidad de Educación Tecnológica Agropecuaria y Ciencias del Mar

\section{Correo Eletrónico}

`doble.tictac@gmail.com

\section{(DORCID}

${ }^{1} \mathrm{https}: / /$ orcid.org/0000-0002-5860-3651

\section{Citar así: C4APA / IEEE}

Abarca-Reyes, J. (2020). Evolución Histórica de las Tecnologías Educativas en México . Revista Tecnológica-Educativa Docentes 2.0, 9(2), 254-263. https://doi.org/10.37843/rted.v9i2.171

J. Abarca-Reyes, "Evolución Histórica de las Tecnologías Educativas en México ", RTED, vol. 9, n. ${ }^{\circ}$ 2, pp. 254-263, sep. 2020.

\section{Resumen}

Durante las últimas décadas han surgido nuevas tecnologías que han impactado la forma como se desenvuelve la educación, dichas tecnologías siguen surgiendo día a día. Por ello el objetivo de esta investigación es hacer un análisis histórico del progreso de dichas tecnologías, con el fin de comprender mejor el fenómeno de manera más global, lo anterior haciendo una proyección hacia el futuro; cabe mencionar que los datos fueron obtenidos mediante un análisis de la información existente en fuentes documentales. Durante el último siglo han sido utilizado variedad de tecnologías que van desde la radio, principalmente en los años de 1920 y 1930; la televisión utilizada principalmente en las décadas de 1940 a 1960. En los años de 1960 a 1995 se popularizaría el sistema educativo modalidad abierta, realizado por conducto de medios audiovisuales. Posteriormente en los años 80's comenzarían a utilizarse computadoras para fines educativos; y desde 1995 ha sido muy común que en las estrategias educativas se haga uso del internet, así como los dispositivos móviles. Para concluir que el uso de la tecnología educativa seguirá evolucionando constantemente, por ello los docentes y autoridades educativas deben de estar preparados para sacar el máximo el máximo provecho de las tecnologías venideras aplicadas al ámbito educativo.

Palabras clave: Tecnología educativa, Historia, Avances tecnologicos, Cronología.

\begin{abstract}
During the last decades have surged new technologies that have impacted the way education unfolds to better understand better the phenomenon more globally. these technologies continue to emerge day by day. Therefore, the objective of this research is to do a historical analysis of the progress of such technologies, the above making a projection towards the future; it is worth mentioning that the data was obtained through an analysis of existing information in documentary sources. During the last century, a variety of technologies have been used ranging from the radio, mainly in the 1920s and 1930s; television used primarily in the 1940 s to 1960 s. In the years 1960 to 1995 the open modality educational system would become popular, made through audiovisual media. Later in the 80 's computers would begin to be used for educational purposes; and since 1995 it has been quite common that in educational strategies use the internet, as well as mobile devices. In conclusion that the use of educational technology will continue to evolve constantly, therefore teachers and educational authorities they must be prepared to get the most out of upcoming technologies applied to the educational field.
\end{abstract}

Keywords: Educative technology, chronological historicity, technological advances. 


\section{Introducción}

La sociedad posee una naturaleza cambiante, pues se ve determinada en cuanto a sus características en función del tiempo y el espacio en el cual se sitúa; por ende, siendo la educación uno de los fenómenos sociales más importantes, es de esperarse que sea también diferente según su situación espacio temporal en la cual se encuentre, de ahí que pueda ser calificada por su naturaleza evolutiva. Lo anterior en lo que refiere a cada uno de los procesos educativos, incluyendo desde luego los procesos de enseñanzaaprendizaje aplicadas en los distintos niveles educativos (CEDEFOP, 2017).

Por tal razón, para comprender mejor el fenómeno de educativo es pertinente obtener el apoyo de otras disciplinas científicas, como son la sociología y la historia. Respecto a la sociología aplicada a la educación; es a través de ella que se analizan los distintos procesos educativos como parte de un fenómeno social, es decir mediante el análisis de las relaciones y hechos sociales acontecidos en el proceso de enseñanza a los alumnos (Castillo, 2012).

Por otra parte, en relación con la historia de la educación, se encarga de estudiar y comprender en que se va transformando el arte de enseñar, como un fenómeno humano, en el transcurso del tiempo. Dichas transformaciones pueden ser de tipo social, económico, político o cultural; como tal dicha disciplina no solo analiza los acontecimientos a lo largo del tiempo, sino además en toda la extensión del espacio geográfico (Gichot, 2006).

Entonces ¿Qué finalidad puede tener el estudiar los acontecimientos trascendentes del pasado en el ámbito educativo? Pues en primera instancia, es de mucha utilidad para poder analizar de forma crítica, como dichos acontecimientos han modificado la forma en que se desarrollan las actividades educativas, así como los beneficios de dichas transformaciones y su impacto en nuestra sociedad actual (Ginestet, \& Meschiany, 2016). Además, por medio del conocimiento histórico es posible analizar la relación causal existente entre el pasado y el presente, así como del pasado con el futuro; por lo que puede afirmarse que los hechos históricos son un medio para hacer una previsión de los acontecimientos de un futuro próximo.

La sociedad cambia de manera constante, pero quizá el ámbito en el cual ha habido mayores cambios durante últimas décadas es la tecnología; misma que a inicios del siglo pasado era concebida aun como parte de la ciencia. Debido a su constante transformación comenzó a ser estudiada desde el siglo anterior, en lo que respecta a los efectos que producidos a nivel social y cotidiano (Tabarez \& Correa, 2014).

La tecnología ha cambiado en gran medida el estilo de vida de las personas, así como la forma en que se llevan a cabo gran parte de las actividades humanas, incluyendo entre ellas las actividades educativas. Es por ello, que la tecnología educativa "por cometido posibilitar la organización de entornos de aprendizaje que proporcionen las condiciones más idóneas para conseguir finalidades educativas, empleando diversos medios tecnológicos" (Cañizales $\&$ Beltran, 2017, p. 36). Cabe precisar que el uso de la tecnología para fines educativos no es un fenómeno muy reciente, sino es un hecho que se ha visto presente a lo largo de la historia (p.36).

Por ello resulta muy importante el poder analizar cómo ha evolucionado la tecnología educativa, dentro del territorio mexicano. Con el fin de poder comprender cuales han sido los principales cambios y beneficios que ha traído su uso para la educación en el pasado, así como al fenómeno educativo actualmente. Del mismo modo, con dicha información se puede estar en condiciones de poder hacer un análisis acerca de cómo puede proyectarse el uso de la tecnología educativa, en futuros cercanos.

\section{Metodología}

La presente es una investigación con un diseño no experimental de tipo longitudinal, con un enfoque meramente cualitativo, a través del cual se recabaron datos históricos; por medio de la intervención realizada a través de un estudio profundo y minucioso de diversas fuentes documentales (primarias y secundarias), tales como libros, revistas, artículos, documentos oficiales, documentos históricos, entre otros, para la posterior organización cronológica de los acontecimientos. Por ser una investigación totalmente cualitativa, no se realizó ningún análisis estadístico de los datos.

La población total está integrada por el conjunto de documentos que se han escrito en torno al tema del uso de las tecnologías educativas dentro del territorio mexicano. Debido a lo anterior, para seleccionar la muestra se llevó a cabo a través de un muestreo no probabilístico, lo anterior basado en aquellos documentos que sean de fácil acceso, y sirvan en 
mayor medida a esta investigación. Por su parte el entorno está conformado por todo el territorio nacional, que es el espacio geográfico en el cual de desarrollan los hechos objeto de la presente investigación.

\section{Resultados}

\section{La Radio y el Cine como Medios de Educación (1920-1940)}

El 21 de julio de 1921, bajo el gobierno de José Vasconcelos se decretó la creación de la Secretaria de Educación Pública; entre los principales los objetivos que se buscaba lograr con dicha creación, era ampliar la cobertura educativa, pues solo un pequeño sector de poblacional tenía acceso a educación pública (Secretaria de Educación Pública, 2015); dicho acontecimiento marco un elemento importante, para la necesidad de incorporar nuevos recursos educativos, con el fin de mejorar la calidad y amplitud en el área educativa.

Posteriormente en la década de 1930, con el auge de la radio como medio masivo de comunicación; se empezó a utilizar alrededor del mundo a dicho medio como recurso educativo, y en México no sería una excepción. Fue así como en el año de 1924 la Secretaria de Educación Pública fundaría su propia estación de radio, con propósitos tanto artísticos como educativos; aunque su alcance social fue algo limitado (Roldán, 2009).

Dicha estación recibía el nombre de CZE-XFX, la cual estuvo al aire entre los años de 1924 y 1937 , de manera inicial tuvo fines predominantemente artísticos; pero con el tiempo fue vista como un modo de hacer llegar contenido educativo a aquellos sectores que no tenían mucho acceso a una educación de tipo presencial, así como medio de apoyo para los maestros rurales. La estación era apoyada por una fuente impresa, llamada inicialmente el "Boletín Oficial de Radio de la Estación CZE"; posteriormente, en 1932, denominada "el maestro rural" (Roldán, 2009).

Otro de los medios de difusión educativa, utilizado por la Secretaria de Educación Pública durante la década de 1930 fue el cine; ya que en el año de 1934 se creó dentro de la SEP una sección de fotografía y cinematografía, misma que se encargaría de producir doce películas educativas anuales. Aunado a lo anterior, al instaurarse el gobierno del
General Lázaro Cárdenas, se vio impulsado la difusión cinematográfica del contenido educativo con la creación de la Casa Productora Cinematográfica Latinoamericana (CLASA), con ella no solo se fomentada la alfabetización de los niños, obreros y campesinos, sino servía, además, como un recurso de difusión política, así como social (Gudiño, 2018).

Al final del gobierno de Cárdenas y al inicio de la década de los 40's, la SEP intento cambiar un poca la forma como se manejaba la filmografía con fines educativos; pues inició el proyecto denominado: Literacy for the Américas, con el cual se incorporó al conocido cineasta Walt Disney quien produjo cuatro cortometrajes, los cuales tenían fines de alfabetización. Aunque dicho proyecto solo llegaría hasta el año de 1944, ya que recibiría críticas de ser muy básico e irrelevante (Gudiño, 2018).

\section{La Televisión Educativa (1948-1970)}

En el mismo periodo de los años 40's, comenzó a cobrar relevancia social otro medio masivo de comunicación: la televisión; por ello, en el año de 1948 fue realizado por parte del Instituto de Bellas Artes un estudió, a través cual se destacarían las principales propuestas educativas de la televisión en Gran Bretaña y Estados Unidos. Por lo cual en el mismo año se llevaría a cabo la primera demostración, en circuito cerrado, de televisión aplicado a la medicina quirúrgica. Posteriormente en 1952, se inauguró el primer sistema de circuito cerrado de apoyo a la docencia de la Escuela Nacional de Medicina de la Universidad Nacional Autónoma de México (Dozal, 2002).

Seria en el año de 1955, cuando la misma UNAM produciría los primeros programas educativos y culturales que serían transmitidos por Telesistema mexicano; como consecuencia de lo anterior en 1959, por conducto del Instituto Politécnico Nacional, se comenzaría a transmitir programas con fines educativos, así como culturales, a través del canal 11 XEIPN, el cual pertenecía a señal abierta (Bosco \& Barrón, 2008).

Para 1960, con el fin de regular la radiodifusión cultural y comercial, entró en vigor la Ley Federal de Radio y televisión, que tenía entre sus objetivos primordiales hacer de dichos medios masivos, instrumentos de educación popular, buscando despertar en los niños valores cívicos, así como el respeto y amor a la patria (Díaz, 1970). Mismo año en 
el cual se crearía la Unidad de Grabación de la Secretaria de Educación Pública, destinada a la producción de medios educativos audiovisuales, principalmente con el fin de apoyar a los maestros rurales (Bosco \& Barrón, 2008).

Poco tiempo después, en 1965, la Secretaria de Educación Pública pondría en marcha el programa denominado "Alfabetización por Televisión”, el cual como su nombre lo indica tenía como fin utilizar el auge de la TV como estrategia para reducir el gran índice de analfabetismo, que durante esos años existía en un porcentaje considerable, de los habitantes de nuestro país (Jiménez, Martínez, \& García, 2010).

\section{El Desarrollo de los Sistemas de Educación Abierta}

El programa Alfabetización por Televisión impulsaría al proyecto de impartir educación secundaria por medio de señales televisivas, a las cuales se les denomina telesecundarias, mismas que estaban basadas en el modelo de "telescola" italiana; lo anterior con el objeto de combatir el rezago educativo en aquellas localidades con menos de 2500 habitantes, y en las por motivo del número de egresados de primaria, o las condiciones de tales localidades fuera imposible establecer secundarias generales o técnicas (Calixto \& Rebollar, 2008).

Dicho proyecto iniciaría en el año de 1968 con 300 teleaulas a nivel nacional, el cual para 1970 se incrementarían a 1163. El equipo que solía utilizarse en las teleaulas era el de un receptor de televisión; más adelante añadirían también el uso de videograbadoras (Bosco \& Barrón, 2008). Cabe precisar que al inicio del proyecto las clases eran grabadas por los telemaestros, lo cual implicaba una carga de trabajo excesiva, así como el uso de muchos recursos, que generaban un costo muy alto; por tal razón se optaría por transmitir una gran mayoría de las clases en vivo (Jiménez, Martínez, \& García, 2010).

Parecía evidente que el sistema de Telesecundarias impartido gracias al uso de las tecnologías influiría en el resto de los niveles educativos. A finales de los años 60's e inicios de los 70 's, fue una época de muchos cambios en la educación superior de México; primeramente, en 1968, había ocurrido el movimiento estudiantil, el cual dejaba de manifiesto la tensión política existente entre el Estado y las universidades públicas. Además, en 1970 se llevó a cabo la asamblea general de la
UNESCO y se creó la Comisión Internacional para el Desarrollo de la Educación, con el objeto de garantizar el derecho a la educación; pues realmente exista mucha exclusión, rezago y abandono educativo de los jóvenes menores de 24 años (Amador, 2012).

En virtud de lo anterior, fue que entre los años 1970 y 1972 se llevaría a cabo en la Universidad Nacional Autónoma de México, una reforma académica universitaria; misma que entre sus puntos importantes destaca la fundación del Sistema de Universidad Abierta (SUA). El cual fue establecido como un sistema libre, buscando aprovechar las experiencias, así como los recursos tecnológicos para reducir los tiempos que los alumnos deban de pasar en las aulas de clases; lo anterior apoyado en recursos tales como el seminario, el libro, además recursos de comunicación en masa, tal es el caso de la radio, cine, televisión, entre otros (Universidad Nacional Autónoma de México, 2014).

Había de esperarse que debido al auge inicial en el uso de las tecnologías educativas, la UNAM no fuera la única institución en aplicar el sistema abierto al nivel educativo superior; así pues fue en 1974 el instituto Politécnico Nacional en la Escuela Superior de Comercio y Administración iniciaría sus actividades la carrera de Comercio Internacional, en modalidad abierta, la cual se denominaría "Sistema Abierto de Enseñanza", conocido por sus siglas SADE (Instituto Politécnico Nacional, 1974.

Cabe precisar que un año antes, se había implementado el sistema abierto en el nivel educativo medio superior. (Gobierno de México, 1973). El 23 de septiembre de 1973 por decreto presidencial seria creado el Colegio de Bachilleres, iniciando sus actividades tanto en modalidad escolarizada, como en no escolarizada; la segunda de las mencionadas denominada Sistema de Enseñanza Abierta (SEA). Dicha modalidad abierta era apoyaba en las tecnologías, principalmente la televisión para proporcionar educación nivel bachillerato en los planteles establecidos de manera inicial en zona metropolitana de la Ciudad de México.

Posteriormente, un año después, sería utilizado el mismo modelo aplicado a la educación tecnológica en nivel bachillerato, ya que la Dirección General de Educación Tecnológica Industrial (DGETI) podría en marcha el Sistema de Educación Tecnológica Industrial, combinando el uso de las tecnologías audiovisuales con estrategias de aprendizaje basadas en el estudio independiente (Barrios, 2007). 
Consecuentemente en el año de 1979 la Secretaria de Educación Pública firmaría un convenio, por medio del cual el Instituto de Latinoamérica de la Comunicación Educativa (ILCE) produciría recursos audiovisuales para el sistema educativo nacional. Un año después la Universidad Pedagógica Nacional ofrecería el Sistema de Educación a Distancia (SEAD), ofreciendo licenciaturas modalidad a distancia en 64 unidades académicas a lo largo del territorio del país (Navarrete \& Manzanilla, 2017).

No solamente la educación en las escuelas se vio impactada por las tecnologías educativas audiovisuales, sino además la educación para el uso cotidiano, dirigida a población mexicana de todas las edades. Pues en el año de 1980 el Sistema Alimentario Mexicano, programa creado para afrontar la crisis agrícola, creó una campaña de medios de comunicación masiva- prensa, radio y televisión- con el fin de educar a todos los mexicanos en general, con el fin de incidir en sus patrones de gasto y consumo (Pedroza, 2018).

El 31 de agosto de 1981, fue creado el Instituto Nacional de Educación de los Adultos (INEA), cuya finalidad era la alfabetización, impartición de educación primaria y secundaria para los adulos, así como su debida acreditación a quienes aprobaran las evaluaciones correspondientes; lo anterior principalmente dirigido a personas adultas, o bien a mayores de 15 años. Para cumplir con sus finalidades el INEA haría uso principalmente de tecnologías audiovisuales (Bosco \& Barrón, 2008).

\section{El Auge de las Computadoras y su Aplicación al Ámbito Educativo}

Durante la década de los 70's las computadoras comenzaron a tener auge a nivel internacional, sobre todo en los Estados Unidos de América; lo cual ocasionó que en nuestro país comenzaran a diseñarse los primeros equipos de cómputo, una de las primeras fuera diseñada a inicios de los años 80's, llamada computadora Heterarquica de Procesamiento Paralelo (Arrollo, Rodríguez \& Coello, 2008). Por lo anterior, en el año de 1984 en nuestro país se llevará a cabo el primer simposio internacional de computación en la educación infantil, - que posteriormente se abriría a todos los niveles educativos- dicho evento seria organizado por el Programa Universitario de Cómputo y la academia de Investigación Científica A.C., con participación de la Secretaria de Educación
Pública, así como diversas secretarias y universidades estatales (Sociedad Mexicana de Computación en la Educación, 2020).

Los avances en el tema de computación se ampliarían en los años posteriores; 1987 la UNAM establecería conexión con red académica de cómputo denominada BITNET, llevado a cabo mediante enlaces telefónicos. La primera conexión se realizaría desde Ciudad Universitaria hasta el Instituto Tecnológico de Estudios Superiores de Monterrey (ITESM) y de ahí a San Antonio, Texas en EUA. Apenas 2 años después, en 1989 sería la misma UNAM quien haría historia, por ser la primera institución en Latinoamérica en incorporarse a internet para uso exclusivamente académico y de extensión al público; lo anterior llevado a cabo por medio de fibra óptica (Universidad Nacional Autónoma de México, S.F.).

En 1990 otros centros educativos serían los siguientes en conectarse a internet, como lo fueron Universidad de las Américas, el Instituto Tecnológico y de Estudios Superiores de Occidente (ITESO), la Universidad de Guadalajara (U de G), el Consejo Nacional de Ciencia y Tecnología (CONACYT), y la Secretaría de Educación Pública (Gutiérrez, 2006). Posteriormente el número siguió avanzando, por lo que con el paso del tiempo más universidades fueron adoptando el internet como parte de sus procesos.

Para el año de 1991 fue creada la Comisión Interinstitucional e Interdisciplinaria de Educación Abierta y a Distancia (CIIEAD), misma que tenía como finalidad primordial el servir de enlace para todas las instituciones educativas, que ofrecieran sistemas abiertos y a distancia. Siendo uno de los principales logros de dicha comisión las reuniones internas de trabajo, a distancia; así como los indicadores de calidad para la educación abierta (Zubieta \& Rama, 2015).

Para el año de 1995 fue que empezaron a aplicarse, los servicios satelitales, telefónicos y de comunicación vía modem a programas educativos; lo anterior por medio de colaboración entre el Sistema Educativo Satelital Mexicano (EDUSAT), y la Unidad de Televisión Educativa, junto con el Instituto Latinoamericano de Comunicación Educativa, así como con universidades que manejaban educación a distancia (Bosco \& Barrón, 2008).

En relación con la educación de nivel medio superior, fue en el año de 1997, cuando se pondría en marcha el proyecto de Educación Media Superior 
Abierta y a Distancia (EMSAD), los cuales tenían como fin hacer llegar educación del nivel educativo a los sectores de la población que no tuvieran acceso; lo anterior mediante técnicas de aprendizaje independiente, utilizando medios tecnológicos como lo son: videos, libros equipo audiovisual, software educativo. Con el tiempo se añadiría el uso del internet, para el desarrollo del proceso de enseñanza- aprendizaje en dichos centros (Maciel \& Munguía, 2010).

\section{El Siglo XXI: El Internet, la Educación a Distancia y las Aplicaciones Móviles}

En el transcurso de los años 2001-2002 se pone en marcha el internet 2, a través de la red Abilene de alcance mundial, orientada por el uso de banda ancha, y una infraestructura de redes robustas para usos académicos. En ese mismo año la SEP creó el sitio web llamado PRONOAP, el cual consistía en una serie de recursos digitales, los cuales se encontraban a disposición de los docentes con fines de actualización magisterial; lo anterior se lograba por medio de utilización de recursos tales como foros de discusión, talleres y guías digitales (Bosco \& Barrón, 2008). Cabe mencionar que el PRONOAP surgió como resultado del plan nacional de desarrollo 2001-2006, en cual se establecía la importancia de fomentar el uso de las Tecnologías educativas.

Entre los años 2003-2006 comenzó a desarrollarse el programa enciclopedia para educación básica, misma que tenía por finalidad relacionar los contenidos de los libros de texto gratuitos con diversos con diversos recursos tecnológicos, como lo son el audio, video y el software; además dicho programa proponía el equipamiento de las aulas de clases con equipo tecnológico como lo son: computador: computadora, proyector y pizarrón interactivo. Enciclopedia incluía algunos recursos interactivos para trabajar en el aula, como lo son: actividades interactivas, fonoteca, biblioteca digital, enciclopedia de Encarta, filmoteca, videoteca, galería de arte, entre otros (Secretaria de Educación Pública, 2012).

Por otra parte, desde inicios de la década pasada empezaron a surgir las primeras plataformas virtuales de aprendizaje, con los fines de crear entornos en los pueda ser más accesible el manejo de los contenidos de aprendizaje en la modalidad a distancia. En el año 2001 surgiría la plataforma conocida como Modular Object Oriented Dynamic Learning (Moodle); posteriormente en el 2002 sería lanzada una plataforma conocida como Atutor; y en 2005 seria Blackboard que introduciría al mercado su plataforma virtual de aprendizaje (Ortega, 2006).

En virtud de lo trascendental que comenzaba a tener en ese entonces la educación totalmente a distancia (mediante el uso del internet), en el 2007 mediante iniciativa de la UNAM se crearía el Espacio Común de Educación Superior a Distancia (ECOSAD), de manera inicial con 7 instituciones educativas de educación superior, a las cuales con el tiempo se irían sumando cada vez más; de tal manera que en el año 2008 eran un total de 42 instituciones participantes. Dicho espacio fue creado con fines de reunir esfuerzos, y con ello reducir la brecha digital en el país, así como mejorar la calidad de educación superior impartida en modalidad a distancia (Zubieta \& Rama, 2015).

Es así como comenzaría a surgir una mayor oferta educativa, sobre todo en los niveles de educación superior y posgrado, ya que la autónoma estudio independiente, iniciativa y gestión del tiempo, que demanda la educación a distancia, encaja perfectamente con los principios de andragogía. Quizá uno de los hechos más relevantes en el tema de universidades a distancia, fue la puesta en marcha por parte de la Secretaria de Educación pública del programa de Educación Superior Abierta y a Distancia (ESAD), lo anterior durante el año 2009. El cual tenía como finalidad satisfacer las necesidades de educación superior a personas, que por cuestiones geográficas, sociales o laborales no pudieran acceder a universidades presenciales; la oferta inicial fue de 12 licenciaturas y 1 Técnico Superior Universitario, mismos que podían ser cursados totalmente por internet (Universidad Abierta y a Distancia de México, 2011).

Tendría tanta aceptación dicho programa, que el ESAD pasaría a convertirse en una universidad. De esa manera, por decreto presidencial en el año 2012 se crearía la Universidad Abierta y a Distancia de México (UnADM), la cual crecería a tal grado que en el año 2018 tendría matriculado a más 41 mil estudiantes, de las 32 entidades federativas. Durante el transcurso de los años han surgido diversas universidades a distancia, en la siguiente tabla hacemos un análisis de algunas de ellas. 


\section{Tabla 1}

Principales universidades de México y su oferta educativa.

\begin{tabular}{|c|c|c|}
\hline Universidad & $\begin{array}{l}\text { Año de } \\
\text { Creación }\end{array}$ & $\begin{array}{c}\text { Oferta educativa actual } \\
(2020)\end{array}$ \\
\hline $\begin{array}{l}\text { Universidad Abierta } \\
\text { y a Distancia de } \\
\text { México (UnADM) }\end{array}$ & 2009 & $\begin{array}{ll}23 \text { licenciaturas con salidas } \\
\text { terminales en TSU, } 1 \\
\text { especialidad, 2 maestrías y } \\
\text { educación continua }\end{array}$ \\
\hline $\begin{array}{l}\text { Polivirtual del } \\
\text { Instituto Politécnico } \\
\text { Nacional (IPN) }\end{array}$ & 2007 & $\begin{array}{l}\text { Bachillerato, } 9 \\
\text { especialidad, licenciatura, } \\
\text { doctorados } \\
\text { continua }\end{array}$ \\
\hline $\begin{array}{l}\text { Universidad Digital } \\
\text { del Estado del } \\
\text { México } \\
\text { (UDEMEX) }\end{array}$ & 2012 & $\begin{array}{l}\text { Bachillerato, } 4 \text { licenciaturas, } 4 \\
\text { maestrías, } 1 \text { doctorado y } \\
\text { educación continua }\end{array}$ \\
\hline $\begin{array}{l}\text { Universidad de } \\
\text { Guadalajara Virtual }\end{array}$ & 2005 & $\begin{array}{l}\text { Bachillerato, } 9 \text { licenciatura, } 1 \\
\text { maestría y educación continua }\end{array}$ \\
\hline $\begin{array}{l}\text { Universidad Virtual } \\
\text { del Estado de } \\
\text { Guanajuato } \\
\text { (UVEG) }\end{array}$ & 2007 & $\begin{array}{l}\text { Bachillerato, } 9 \text { licenciatura, } 5 \\
\text { maestrías y educación continua }\end{array}$ \\
\hline $\begin{array}{l}\text { Universidad Virtual } \\
\text { del estado de } \\
\text { Michoacán } \\
\text { (UNIVIM) }\end{array}$ & 2010 & $\begin{array}{l}6 \text { licenciaturas, } 16 \\
\text { especialidades, } 19 \text { maestrías, } 5 \\
\text { doctorados y educación } \\
\text { continua }\end{array}$ \\
\hline $\begin{array}{lr}\text { Instituto } & \text { Consorcio } \\
\text { Clavijero } & \text { de } \\
\text { Veracruz } & \end{array}$ & 2012 & $\begin{array}{l}\text { Bachillerato, } 7 \text { licenciatura, } 2 \\
\text { maestrías y educación continua }\end{array}$ \\
\hline
\end{tabular}

Nota. En base a la información contenida en los sitios web institucionales, elaboración propia.

Cabe precisar que no solo el nivel de educación superior se ha visto beneficiado por la creación de instituciones que procuren impartición de la educación a distancia, sino además lo ha sido en el nivel medio superior. Quizá el acontecimiento más relevante del tema se trate de la creación del servicio de bachillerato en línea conocido como "Prepa en Línea" por parte de la SEP, durante el 2015; creado con los fines de poder proveer del servicio de educación media superior, a todos aquellos habitantes que no puedan tener acceso a los bachilleratos presenciales, dentro de cualquier parte del territorio de la República Mexicana (Tuirán, Limón \& González, 2015).

Por otra parte, las recientes reformas legislativas y administrativas en materia de educación han propiciado el fomento del uso de diferentes tecnologías educativas en el contexto educativo. Primeramente, en lo referente a la educación secundaria, el 26 de mayo del 2006 se emitió el acuerdo secretarial número 384 "por el que se establece el nuevo plan y programas de estudio para Educación Secundaria", el cual en primer lugar se establece la inclusión de "Tecnología" como asignatura del currículo nacional; además se recalca la importancia de que los jóvenes de dicho nivel educativo comprendan lo importancia que son la ciencia y tecnología en la sociedad, y asimismo desarrollen competencias tecnológicas necesarias para su desenvolvimiento en su día a día (Secretaria de Educación Pública, 2006).

En lo que respecta al nivel bachillerato con la Reforma Integral de la Educación Media Superior (RIEMS), habría algunos cambios al sistema educativo en el nivel. Inicialmente en el acuerdo secretarial 444 "por el que se establecen las competencias que constituyen el marco curricular común del Sistema Nacional de Bachillerato.”, en el cual se definieron las competencias tecnológicas que los estudiantes deben de desarrollar en cada una de las asignaturas, hablando tanto de competencias genéricas como disciplinares (Secretaria de Educación Pública, 2008). Además, en el acuerdo 445 "por el que se conceptualizan y definen para la Educación Media Superior las opciones educativas en las diferentes modalidades", en cual reconoce a la educación virtual como uno de los medios y modalidades por conducto de la cual puede impartirse educación de nivel medio superior; mencionando lo importante que es la mediación digital, como forma de comunicación entre alumnos y docentes (Secretaria de Educación Pública, 2008 b).

Durante los últimos años se ha incrementado la oferta de cursos que se ofrecen modalidad a distancia por medio de internet, pero quizá lo más sobresaliente fue el desarrollo de los llamados Massive Open Online Courses (MOOC) los cuales desde el año 2013 se imparten desde diversas plataformas en México (Navarrete \& Manzanilla, 2017). Los MOOC's aportan muchas ventajas, como lo son la disponibilidad de horario, la gran cantidad de usuarios que pueden participar en ellos, así como una gran variedad de recursos didácticos utilizados; en virtud de lo anterior se han popularizado mucho, durante los últimos años. A continuación, se mencionan las principales plataformas para de MOOC's así como el año en de surgimiento de la plataforma. 
Tabla 2

Plataformas de MOOC más utilizadas en México.

\begin{tabular}{ccc}
\hline Plataforma & $\begin{array}{c}\text { Año de } \\
\text { Surgimiento }\end{array}$ & Enlace del sitio web \\
\hline Coursera & 2012 & Es.coursera.org \\
\hline Future Learn & 2012 & www.futurelearn.com \\
\hline Edx & 2012 & www.edx.org \\
\hline MiradaX & 2013 & Miriadax.net \\
\hline México X & 2015 & www.mexicox.gob.mx \\
\hline $\begin{array}{c}\text { "Capacitación } \\
\text { para el empleo" } \\
\text { de la Fundación } \\
\text { Carlos Slim }\end{array}$ & 2016 & Capacitateparaempleo.org \\
\hline
\end{tabular}

Nota. En base a la información de contenidos en los sitios web institucionales, elaboración propia.

\section{La Pandemia de Covid-19 y la Necesidad de Trabajar a Distancia en todos los Niveles Educativos}

A finales del año 2019 surgirían en China los primeros brotes del virus COVID-19, mismos que comenzarían a expandirse de manera rápida en las distintas regiones del país asiático; para posteriormente comenzar a propagarse en otras naciones. A finales de febrero se presentaría el primer caso de COVID en México, por lo que durante el mes de marzo la Organización Mundial de la Salud declararía pandemia mundial por el virus antes descrito (Díaz \& Toro, 2020). Lo anterior traería como consecuencia que en nuestro país se tomaran medidas, para evitar que propagará el virus, evitando el contacto físico de los individuos en las actividades, incluyendo a actividades educativas. Por tal virtud, en el mes de abril se comenzarían a desarrollar estrategias para llevar a cabo las actividades educativas modalidad a distancia, mediante el uso de las tecnologías educativas.

En razón a lo anterior, hubo mucha necesidad de educación a distancia por medio de las tecnologías educativas en dos sentidos. En primer lugar, la formación académica de los docentes hacia los alumnos, en cada uno de los niveles educativos, con el fin de cumplir con el ciclo escolar; y además hubo mucha educación hacia los docentes, para capacitarlos en las distintas herramientas digitales que tenían a sus disposiciones, así como de estrategias de trabajo a distancia.

De acuerdo con Mancera, Serna \& Barrios (2020) para atender dichas actividades educativas a distancia, las herramientas tecnológicas más utilizadas por los docentes fueron las siguientes:
1. Aplicaciones para reuniones virtuales (Zoom, Google Meet, GoToMeeting).

2. Redes sociales, así como servicios de mensajería instantánea (WhatsApp, Facebook).

3. Páginas web con contenido de aprendizaje.

4. Correo electrónico.

5. Servicio de alojamiento de videos $\mathrm{y}$ transmisión en directo (YouTube).

6. Servicio de alojamiento en la nube.

En lo que respecta a la educación con fines de capacitación para los docentes, los cursos principalmente fueron dirigidos a instruir sobre el manejo de herramientas tecnológicas disponibles, así como al desarrollo de las competencias digitales y el diseño de estrategias para el para el trabajo a distancia; también fueron desarrollados cursos para el manejo de la inteligencia emocional de los docentes en tiempos de confinamiento.

\section{Conclusiones}

En los últimos 100 años los acontecimientos relativos al desarrollo y aplicación de las tecnologías en los contextos educativos, ha sido de naturaleza muy cambiante, además con muchos progresos. Lo anterior, tomando en consideración los recursos tecnológicos que se han utilizado, los cuales han sido muy variados; partiendo de la radio, la televisión, los demás medios audiovisuales, la computadora, el internet, los dispositivos y aplicaciones móviles.

Con base a lo anterior, podemos afirmar que los avances tecnológicos aplicables al campo formativo de los estudiantes seguirán avanzando al mismo ritmo o quizá a un ritmo superior a las décadas pasadas. Pues por una parte los recursos tecnológicos actuales, como son los derivados de los smartphones y el internet se diversifican, acomplejándose cada vez más; por otra parte, surgen otros recursos, como lo son realidad virtual y la inteligencia artificial, los cuales día con día están transformando los distintos procesos educativos que se llevan a cabo en las escuelas.

Por ello, todos los actores educativos deben estar preparados a los nuevos cambios que pudieran suscitarse por motivo de los progresos tecnológicos. Por una parte, resulta muy conveniente que los docentes se encuentren debidamente informados 
sobre las novedades en el presente tema; así como debidamente capacitados en el manejo de las tecnologías educativas, así como el desarrollo de estrategias basadas en ellas: lo anterior para el diseño $\mathrm{y}$ fomento de las actividades de enseñanzaaprendizaje.

Por otra parte, debe de ser labor de las autoridades en la materia, el diseño de distintas políticas y normatividades, por medio de las cuales puedan ser diseñados los debidos procesos educativos; con el fin de obtener el máximo provecho, adecuado manejo de las tecnologías; de esa manera poder obtener los mejores resultados de aprendizaje, así como el desarrollo integral de los educandos, en los distintos niveles educativos. Además de ello, es conveniente que las escuelas y distintas instituciones educativas, cuenten con una debida infraestructura y equipamiento con el fin de poder llevar a cabo los procesos educativos basados en las tecnologías acorde con los objetivos de aprendizaje para cada grado y nivel en concreto.

Hoy en día la educación y tecnología parecen conformar un binomio, de tal manera que es imposible imaginar la una sin la otra; aún mejor, pareciera que ambas se nutren mutuamente, complementándose. Por ello resulta muy importante desarrollar procesos, así como sistemas de enseñanza en los que ambas operen de manera conjunta, para así buscar formar de manera más amplia a los estudiantes en el uso y desarrollo de la tecnología; a la vez con la educación formar ciudadanos los cuales por medio dichas tecnologías fomenten el crecimiento $\mathrm{y}$ desarrollo de la sociedad en la cual se desenvuelven.

\section{Referencias}

Amador, R. (2012). 40 años del Sistema Universidad Abierta de la UNAM. Crónica Histórica. Perfiles educativos. 34 (137). 194$212 . \quad$ Recuperado de: http://www.scielo.org.mx/pdf/peredu/v34n137/v34n137a12.pd $\mathrm{f}$

Arrollo, D., Rodríguez, F. \& Coello, C. (2008). Computadoras mexicanas: una breve reseña técnica e histórica. Revista Digital Universitaria. 9 (9). 1-21. Recuperado de: http://www.revista.unam.mx/vol.9/num9/art63/art63.pdf

Barrios, H. (2007). Los estudiantes del Sistema Abierto de Educación Tecnológica Industrial (SAETI): una valoración de la modalidad educativa desde la perspectiva escolar. Universidad Pedagógica Nacional. Recuperado de: http://200.23.113.51/pdf/24286.pdf

Bosco, M. \& Barrón, H. (2008). La Educación a distancia en México: narrativa de una historia silenciosa. Universidad Nacional Autónoma de México. Recuperado de: https://bit.ly/3g5iRpo
Calixto, R. \& Rebollar, A. (2008). La Telesecundaria, ante la sociedad del conocimiento. Revista Iberoamericana de educación. 44(7). 1-11. Recuperado de: https://rieoei.org/historico/expe/2197Flores.pdf

Cañizales, P. \& Cobo, J (2017). Tecnología educativa y su papel en el logro de los fines de la educación. Revista Venezolana de Educación. 21(68). 31-40. Recuperado de: https://www.redalyc.org/pdf/356/35652744004.pdf

Castillo, J. (2012). Sociología de la educación. Red Tercer Milenio. Recuperado

de: http://www.aliat.org.mx/BibliotecasDigitales/Educacion/Socio logia_de_la_educacion.pdf

Díaz, V. (1970). Antecedentes cronológicos de la Ley Federal de Radio y Televisión. Universidad Autónoma de México. Recuperado de: https://archivos.juridicas.unam.mx/www/bjv/libros/5/2444/5.p df

Diaz, F, \& Toro A. (2020). SARS-CoV-2/COVID-19: el virus, la enfermedad y la pandemia. Revista de Medicina y Laboratorio. 24 (1). 183-205. Recuperado de: http://docs.bvsalud.org/biblioref/2020/05/1096519/covid19.pdf

Dozal, J. (2002). La televisión educativa en México [ponencia]. Segundo congreso de imagen y tecnología. Mazatlán, México. Recuperado https://www.academia.edu/5400829/Tv_educativa

European Centre for the Development of Vocational Training (2017). The changing nature and role of vocational education and training in Europe Volume 2. Luxembourg: Publications Office of the European Union. Recuperado de: https://www.cedefop.europa.eu/files/5564_en.pdf

Ferreira, R. \& Madrigal, M. (2014). Desarrollo de aplicaciones moviles para la enseñanza de las ciencias. Revista ReCIBE. 3 (1). Recuperado de: http://revistascientificas.udg.mx/index.php/REC/article/downl oad $/ 5193 / 4850$

Garcia, J., Rodriguez, R. \& Moreno, A. (2016). Apps educativas: una alternativa del siglo XXI. Revista de Sistemas y Gestión Educativa. 3 (7). 10-22. Recuperado de: https://www.researchgate.net/publication/321491922_Apps_e ducativas_una_alternativa_educativa_del_siglo_XXI

Gichot, V. (2006). Historia de la educación: reflexiones sobre su objeto, ubicación epistemológica, devenir, devenir histórico y tendencias actuales. Revista Latinoamericana de Estudios Educativos. 2(1). 11-51. Recuperado de: https://www.redalyc.org/pdf/1341/134116859002.pdf

Ginestet, M. \& Meschiani, T. (2016). Historia de la educación Culturas escolares, saberes, disciplinamiento de los cuerpos. Editorial de la Universidad de la Plata. Argentina. Recuperado de: http://sedici.unlp.edu.ar/bitstream/handle/10915/52231/Docum ento_completo_.pdf-PDFA.pdf? sequence $=3$ \&isAllowed $=\mathrm{y}$

Gobierno de México (2020). Colegio de Bachilleres. ¿Qué hacemos? Ciudad de México. Gobierno de México. Recuperado de: https://www.gob.mx/bachilleres/que-hacemos 
Gudiño, M. (2018). Un recorrido Filmografico por la Secretaria de Educación Pública. Revista Tempos e Espaços em Educação. 11 (26). 91-112. Recuperado de: https://bit.ly/2OQwlJG

Gutierrez, F. (20 de mayo del 2020). La evolución de Internet en México y su impacto en el ámbito educativo (De 1986 a 2006). Blog Ferguz. Recuperado de: https://www.fergut.com/la-evolucionde-internet-en-mexico-y-su-impacto-en-el-ambito-educativode-1986-a-2006/

Instituto Politecnico Nacional (1974). Historia de la Escuela Superior de Comercio y Administración. Gobierno de México. Recuperado https://www.escasto.ipn.mx/conocenos/historia.html

Jimenez, J., Martinez, R. \& Garcia, C. (2010). La telesecundaria en México: un breve recorrido. Secretaria de Educación Pública. Recuperado de: http://www.sepbcs.gob.mx/contenido/documentos/educativo/tel esecundarias/Breve $\% 20$ Historia $\% 20 \mathrm{de} \% 20$ Telesecundaria $\% 20$ en\%20Mexico.pdf

Maciel, M. \& Murguía, M. (2010). La educación media superior a distancia en México y sus efectos para la equidad educativa. Revista Apertura. 10 (1). 1-11. Recuperado de: https://www.redalyc.org/pdf/688/68813176003.pdf

Mancera, C., Serna, L. \& Barrios, M. (29 de abril del 2020). Pandemia: maestros, tecnología y desigualdad. Nexos, blog de educación. Recuperado de: https://educacion.nexos.com.mx/?p=2286

Navarrete, Z. \& Manzanilla, H. (2017). Panorama de la educación a distancia en México. Revista Latinoamerica de Estudios Educativos. 13 (1). 65-82. Recuperado de: https://www.redalyc.org/pdf/1341/134152136004.pdf

Ocaña, M. (2011). Programa de Educación Superior Abierta y a Distancia Universidad Abierta y a Distancia de México. Universidad Abierta y a Distancia de México. Recuperado de: https://sep.gob.mx/work/models/sep1/Resource/921/1/images/e lmodeloedsupabdistancia.pdf

Ortega, A. (2006). Las tecnologías educativas en el contexto de la educación mexicana. Revista Innovación Educativa. 6 (31). 47 58. Recuperado de: https://www.redalyc.org/pdf/1794/179421073005.pdf

Pedroza, L. (2018). El Sistema Alimentario Mexicano: su acción en el campo y en la alimentación, 1980-1982. Revista de Historia y Geografía. 39 (1). 21-48. Recuperado de: https://dialnet.unirioja.es/descarga/articulo/7369103.pdf

Roldan, E. (2009). Los orígenes de la radio educativa en México y Alemania. Revista Mexicana de Investigación Educativa. 14 (40). 13-41. Recuperado de: http://www.comie.org.mx/documentos/rmie/v14/n040/pdf/4000 3.pdf

Secretaria de Educación Pública (2006). ACUERDO número 384 por el que se establece el nuevo Plan y Programas de Estudio para Educación Secundaria. Diario Oficial de la Federación. Recuperado de: https://www.sep.gob.mx/work/models/sep1/Resource/ca8cef5b610b-4d55-8a52-03f1b84d0d6c/a384.pdf
Secretaria de Educación Pública (2008). ACUERDO número 444 por el que se establecen las competencias que constituyen el marco curricular común del Sistema Nacional de Bachillerato. Diario Oficial de la Federación. Recuperado de: https://transparencia.info.jalisco.gob.mx/sites/default/files/u 149/ACUERDO\%20444.pdf

Secretaria de Educación Pública (2008b). ACUERDO número 445 por el que se conceptualizan y definen para la Educación Media Superior las opciones educativas en las diferentes modalidades. Diario Oficial de la Federación. Recuperado de:

https://www.sep.gob.mx/work/models/sep1/Resource/7aa2c 3ff-aab8-479f-ad93-db49d0a1108a/a445.pdf

Secretaria de Educación Pública (2012). Libro blanco programa "enciclomedia" 2006-2012. Gobierno de México. Recuperado de: https://www.sep.gob.mx/work/models/sep1/Resource/2959/ 4/images/LB\%20Enciclomedia.pdf

Secretaria de Educación Pública (2015). Historia de la Secretaria de Educación Pública. Gobierno de México. Recuperado de: https://www.gob.mx/sep/acciones-y-programas/historia-dela-secretaria-de-educacion-publica-15650?state=published

Sociedad Mexicana de Computación en la Educación (2020). Simposio Internacional "La computación en la educación infantil". SOMECE. Recuperado de: https://www.somece.org.mx/1984/10/simposio.html

Tabarez, J. \& Corea, S. (2014). Tecnología y sociedad: una aproximación a los estudios sociales de la tecnología. Revista Iberoamericana de Ciencia, Tecnología y Sociedad. 9 (1). 129-144. Recuperado de: https://www.redalyc.org/pdf/924/92430866007.pdf

Tuirán, R., Limón, O. \& González, G. (2015). "Prepa en Línea-sep", un servicio innovador. Revista mexicana de educación a distancia. Recuperado de: http://revistas.unam.mx/index.php/rmbd/article/download/5 $7370 / 50919$

Universidad Nacional Autónoma de México (S.F.). Cronología. Acervo histórico del cómputo en la UNAM. Recuperado de: http://www.historiadelcomputo.unam.mx/cronologia.html\#. Xza6aqeg_IV

Universidad Nacional Autónoma de México (2014). Modelo educativo del Sistema Universidad Abierta y a Distancia de la UNAM. Coordinación de la Universidad Abierta y a Distancia UNAM. Recuperado de: http://www.cuaed.unam.mx/consejo/interiores/MODELO_S UAYED.pdf

Zabieta, J., \& Rama, C. (2015). La educación a distancia en México: una nueva realidad universitaria. Virtual Educa. Recuperado de: https://www.ses.unam.mx/curso2016/pdf/18-novZubieta_Educacion_distancia.pdf 